\title{
Breaking down barriers to surgical learning in times of COVID-19: an initiative of future surgeons
}

\author{
Michael Gregorio Ortega-Sierra • Jairo Ivan Charry-Caicedo · Angélica Tatiana Orrego-Torres • \\ Leonardo Rueda-Ibarra · Ivan David Lozada Martínez
}

Received: 17 April 2021 / Accepted: 22 April 2021 / Published online: 19 May 2021

C Springer-Verlag GmbH Austria, part of Springer Nature 2021

\section{Dear Editor,}

We read with great interest the article recently published by Vailas et al. [1] entitled "The impact of COVID-19 on surgical training at a tertiary hospital in Greece: a 'hidden infectious enemy' for junior surgeons?" Although junior surgeons and surgical residents have been directly affected by modifications in action protocols, practice time, attendance at certain types of surgeries, and restriction on entry to practice settings, depending on their degree of preparation and advancement in their specialty [2], they arguably have an advantage over those who have not even had their first surgical rotation, or those who aspire to be surgeons and for whom the time spent on surgery and medical rounds has been minimal [3]. This is why medical students, who will be trained to be the surgeons of the future, are the most affected by this public calamity of global scale.

Participation in surgical interest groups is an innovative and effective strategy to promote knowledge and receive support from senior surgeons with extensive experience and academic background [4].

\section{G. Ortega-Sierra, MD \\ School of Medicine, Rafael Nuñez University Corporation, Cartagena, Colombia}

J. I. Charry-Caicedo, MD · L. Rueda-Ibarra, MD School of Medicine, University of Applied and Environmental Sciences, Bogota, Colombia

A. T. Orrego-Torres, MD

School of Medicine, University of Manizales, Manizales, Colombia

I. D. Lozada Martínez, MS (凶)

Medical and Surgical Research Center, University of

Cartagena, Cartagena, Colombia

ivandavidloma@gmail.com
Seminars, conferences, planning and monitoring of research projects, mentoring, and directed activities, among others, constitute the action plan of the interest groups. Those authors who have evaluated and reported on the impact of surgical interest groups on medical students observe enthusiasm, improved empathy with residents and surgeons, promotion of knowledge, and satisfaction [4]. In view of the above, the massive creation of surgical interest groups in medical schools around the world is an option that can help reinforce the learning process, in the face of difficulties such as lack of clinical training and faceto-face teacher-student interaction. An advantage of these groups is that they can be led and coordinated by medical students, putting into practice the mentoring process from the early stages of their career.

Considering that the course of the Coronavirus Disease 2019 (COVID-19) pandemic cannot be predicted with certainty, the programs proposed by medical students with an interest in surgery and residents should be supported, so that the learning curve can be maintained over time and contribute to meeting the objectives of global surgery, among which are mentoring, accompanying medical students throughout their careers, strengthening academic surgery, and intensifying actions to implement evidence-based surgery in order to address the public health problems of each nation.

Conflict of interest M.G. Ortega-Sierra, J.I. Charry-Caicedo, A.T. Orrego-Torres, L. Rueda-Ibarra, and I.D. Lozada-Martínez declare that they have no competing interests.

\section{References}

1. Vailas M, Sotiropoulou M, Mulita F, Drakos N, Ambalov E, Maroulis I. The impact of COVID-19 on surgical training at atertiaryhospital in Greece: a 'hidden infectious enemy' for 


\section{letter to the editor}

junior surgeons? Eur Surg. 2021; https://doi.org/10.1007/ s10353-021-00699-8.

2. Research Education INnovation in Surgery (REINS) initiative COVID-19 group, Yiasemidou M, Tomlinson J, Chetter I, Shenkar BC. Impact of theSARS-CoV-2 (COVID-19) crisis on surgical training: global survey and a proposed framework for recovery. BJS Open. 2021;5(2):zraa51. https://doi.org/ 10.1093/bjsopen/zraa051.

3. Lozada-Martínez I, Bolaño-Romero M, Moscote-Salazar L, Torres-Llinas D. Letter to the editor: 'medical education in times of COVID-19: what's new in neurosurgery? World Neurosurg. 2020;143:603. https://doi.org/10.1016/j.wneu. 2020.07.215.

4. Vakayil V, Chandrashekar M, Hedberg J, et al. An undergraduate surgery interest group: introducing premedical students to the practice of surgery. Adv Med Educ Pract. 2020;11:339-49. https:// doi.org/10.2147/AMEP.S245234.

Publisher's Note Springer Nature remains neutral with regard to jurisdictional claims in published maps and institutional affiliations. 